\title{
HbA1C AS A SCREENING BIOMARKER OF DYSLIPIDEMIA IN TYPE 2 DIABETES MELLITUS PATIENTS
}

\section{S L Sharma ${ }^{1}$, Jigar Shaherawala ${ }^{* 2}$, Ketan mangukiya ${ }^{3}$}

${ }^{1}$ Associate Professor, Department of biochemistry, Smt NHL MMC, Ahemdabad Gujarat, India.

${ }^{* 2}$ Assistant Professor, Department of biochemistry, Smt NHL MMC, Ahemdabad Gujarat, India.

${ }^{3}$ Assistant Professor, Department of biochemistry, Parul Institute of medical science and Research, Vadodara, Gujarat, India.

\section{ABSTRACT}

Background: Diabetes mellitus is a disease of the pancreas, an organ behind your stomach that produces the hormone insulin. Insulin helps the body use food for energy. Blood sugar level is found to be high in Diabetes mellitus.

Aim: The Aim is to study roll of $\mathrm{HbA1c}$ as screening biomarker of dyslipidemia in Type 2 Diabetes mellitus patients.

Methodology: Study consists of 140 type 2 DM patients of 40-60 year age group along with age and sex matched healthy control. Fasting Blood samples were collected from all participants for measurement of Lipid profile, Blood sugar(FBS) and HbA1c .

Results: In case group, The mean concentration of Fasting blood glucose $(\mathrm{mg} / \mathrm{dl})$, S.Cholesterol(mg/dl), S.Triglyceride $(\mathrm{mg} / \mathrm{dl}), \mathrm{S} . \mathrm{HDL}(\mathrm{mg} / \mathrm{dl})$ and $\mathrm{HbA} 1 \mathrm{c}(\%)$ is $153.2 \pm 5.2,245.9 \pm 9.5,210.5 \pm 5.230 .52 \pm 6.3$ and $9.7 \pm 1.0$ Respectively while in control group it is $94.5 \pm 6,148.3 \pm 8.5,118.6 \pm 7.3,44.5 \pm 3.2$ and $5.4 \pm 0.5$ respectively.

Conclusion: There is significant positive correlation is found between HBA1C and dyslipidemia. So HBA1C is not only a useful biomarker of long-term glycemic control but also a good predictor of lipid profile.

KEY WORDS: Dyslipidemia, HbA1c, Type 2 DM.

Address for correspondence: Dr Jigar Shaherawala, E-101 Maruti heritage, b/h Maruti Plaza, Sardarchowk road, Vijaypark, Krishnanagar, Ahmedabad, Gujarat, India.

E-Mail: Jigarshaherawala11111 @gmail.com

\begin{tabular}{|l|lr|}
\hline \multicolumn{3}{|c|}{ Online Access and Article Informtaion } \\
\hline Quick Response code & \multicolumn{1}{|c|}{ International Journal of Integrative Medical Sciences } \\
& \multicolumn{1}{|c|}{ www.imedsciences.com } \\
\cline { 2 - 3 } & Received: 19-06-2017 & Accepted: 10-07-2017 \\
Dol: 10.16965/ijims.2017.106 & Reviewed: 20-06-2017 & Published: 05-08-2017 \\
\hline Source of Funding: Self & \multicolumn{2}{c}{ Conflicts of interest: None } \\
\hline
\end{tabular}

\section{BACKGROUND}

Dyslipidemia is a metabolic disorder in which there is deficiency or overproduction of liporptein and cholesterol levels are occurred. The level of total choletsrol,Low density lipoprotein( $L D L)$, and Triglyceride is found to be increased while level of High density lipoprotein (HDL) is decreased so that there is increased risk of atherosclerosis and subsequently blood vessels blockadge [1].
In India day by day the prevalence of diabetes malitus is increased that may be due to high degree of genetic predisposition . In India alone, 31.7 million people had diabetes in year 2000 which latter on increased to 61.3 million in 2011 and is ex-pected to reach 101.2 million by 2030 (International Diabe-tes Federation). Thus India is the $2^{\text {nd }}$ largest country in world diabetes prevalence [2].

Early diagnosis and treatment of diabetes is 
mandatory otherwise it leads to various fatal complication like diabetic neuropathy, diabetic nephropathy, diabetic retinopathy, Coronary heart disease etc. and all these complication is occurred due to disturbance of lipid metabolism due to deficiency of insulin [3].

Apart from measurement of blood glucose ,Glycated hemoglobin (HBA1C) is now a day very preferred test because it does not required any special preparation like fasting condition. HBA1C measures blood glucose of Ist 8-12 weeks of time and it is good indicator for prognosis of disease also [4].

The aim of the study was to examine the impact of the glycemic control on the lipid profile of Type 2 diabetic patients and to know the importance of HBA1C as an indirect indicator of dyslipidemia.

\section{MATERIALS AND METHODS}

This retrospective study was conducted at department of biochemistry at smt NHL municipal medical college, and attached V.S General hospital ,Ahmedabad, Gujarat, India from 2015-2016.

Study includes 140 Type 2 Diabetes mellitus patients of age group 40-60 year who visited medicine OPD of our hospital along with 140 age and sex matched healthy control.

Fasting venous blood samples was collected from all participants. Samples were centrifugated at clinical biochemistry laboratory at 3000 RPM for a period of 10 minutes .Serum was separated from all samples.An Uniq was given to all participants. Lipid profile,Blood sugar(FBS) and $\mathrm{HbA1c}$ was measured from all samples by colorimetric method.

Blood Sugar was estimated by Hexokinase method, Glycated hemoglobin(HbA1C) by turbidimetry method, Lipid profile(total cholesterol, triglycerides, HDL-C and LDL-C )out of which total cholesterol(TC) ${ }^{\complement}$, triglycerides(TG) and HDL-C are estimated by different enzymatic end-point methods. LDL-C estimation is done by precipitation method.

Adult Treatment Panel III(ATP III) guideline was used which defined hypercholesterolemia(total cholesterol $>200 \mathrm{mg} / \mathrm{dl}$ ), high LDL-C when value $>100 \mathrm{mg} / \mathrm{dl}$, hypertriglyceridemia when value
$>50 \mathrm{mg} / \mathrm{dl}$ and low HDL-C when value $40 \mathrm{mg} /$ dl. Obtained results of case group was compared with control group for determination of difference of significance.

P-value was calculated by using online student t-test calculator. $p$-value less than 0.05 was consider as significant.

\section{RESULT AND DISCUSSION}

Study was conducted at department of biochemistry smt NHL municipal medical college and attached V.S general hospital ,Ahmedabad, Gujarat, India and it consist of 140 patients of Type $2 \mathrm{DM}$ and 140 Healthy control.

Participants were divided according their age. (Table 1)

Comparison of various biochemical parameter between case group and control group was done by calculating $p$-value. (Table 2 )

Correlation of $\mathrm{HbA} 1 \mathrm{C}$ with lipid profile of diabetes type 2 patients is mentioned in Tab. 3.

Table 1: Age wise distribution of participants.

\begin{tabular}{|c|c|c|c|}
\hline Group & $\begin{array}{c}\text { Number } \\
\text { (n) }\end{array}$ & $\begin{array}{c}\text { Age Group } \\
\text { (yr) }\end{array}$ & Mean Age \\
\hline $\begin{array}{c}\text { Group 1 } \\
\text { (Case) }\end{array}$ & 140 & $40-60$ & $55.2 \pm 4$ \\
\hline $\begin{array}{c}\text { Group 1 } \\
\text { (Control) }\end{array}$ & 140 & $40-60$ & $54.3 \pm 6$ \\
\hline
\end{tabular}

Table 2: Comparison of various biochemical parameter case group and control group.

\begin{tabular}{|l|c|c|c|}
\hline \multicolumn{1}{|c|}{ Parameter } & $\begin{array}{c}\text { Group 1 } \\
\text { (Case) } \\
{[\mathrm{n}=140]}\end{array}$ & $\begin{array}{c}\text { Group 1 } \\
\text { (Control) } \\
\text { [n=140] }\end{array}$ & p-Value \\
\hline $\begin{array}{l}\text { Fasting blood glucose } \\
\text { (FBS)(mg/dl) }\end{array}$ & $153.2 \pm 5.2$ & $94.5 \pm 6$ & $<0.05(\mathrm{~S})$ \\
\hline S.Cholesterol(mg/dl) & $245.9 \pm 9.5$ & $148.3 \pm 8.5$ & $<0.05(\mathrm{~S})$ \\
\hline S.Triglyceride(mg/dl) & $210.5 \pm 5.2$ & $118.6 \pm 7.3$ & $<0.05(\mathrm{~S})$ \\
\hline S.HDL(mg/dl) & $30.52 \pm 6.3$ & $44.5 \pm 3.2$ & $<0.05(\mathrm{~S})$ \\
\hline S.VLDL(mg/dl) & $42.1 \pm 4.2$ & $23.72 \pm 5.6$ & $<0.05(\mathrm{~S})$ \\
\hline S.LDL(mg/dl) & $173.28 \pm 10.5$ & $80.08 \pm 8.5$ & $<0.05(\mathrm{~S})$ \\
\hline HbA1c(\%) & $9.7 \pm 1.0$ & $5.4 \pm 0.5$ & $<0.05(\mathrm{~S})$ \\
\hline
\end{tabular}

\section{S: Significant , NS: Non significant}

In the study, it was found that Serum total Cholesterol, triglyc-erides, VLDL and LDL-C were significantly higher in diabetic type 2 group than control group and were in borderline high risk range. While serum HDL-C was significantly lower in dia-betic type 2 group than control group and was towards lower range of normal value. Thus the study showed the high preva-lence of dyslipidemia, a well known risk factor for 
cardiovascu-lar disease.Thus the findings were in consistent with previ-ous studies $[5,6]$.

Graph 1: Graphical presentation of Comparison of various biochemical parameter case group and control group.

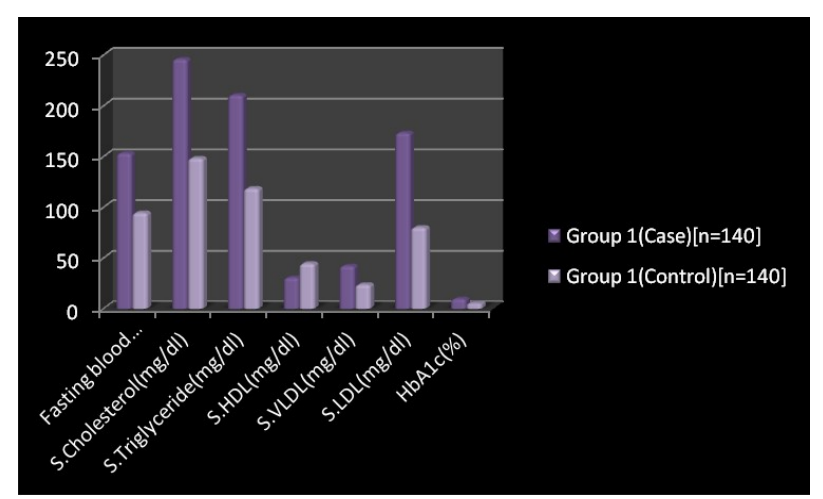

Table 3: Correlation of $\mathrm{HbA1C}$ with lipid profile of diabetes type 2 patients.

\begin{tabular}{|l|c|c|}
\hline \multicolumn{1}{|c|}{ Parameter } & $\begin{array}{c}\text { Corelation } \\
\text { coefficient }\end{array}$ & p-value \\
\hline S.Cholesterol (mg/dl) & 0.56 & $<0.05(\mathrm{~S})$ \\
\hline S.Triglyceride (mg/dl) & 0.91 & $<0.05(\mathrm{~S})$ \\
\hline S.HDL (mg/dl) & -0.2 & $>0.05(\mathrm{NS})$ \\
\hline S.LDL (mg/dl) & 0.52 & $<0.05(\mathrm{~S})$ \\
\hline S.VLDL (mg/dl) & 0.33 & $<0.05(\mathrm{~S})$ \\
\hline
\end{tabular}

S: Significant , NS: Non significant

This study reveals high prevalence of hypercholesterolemia, hypertriglyceridemia, high LDL-C and low HDL-C levels which are well known risk factors for cardiovascular diseases. Insulin affects the liver apolipoprotein production. It regulates the enzymatic activity of lipoprotein lipase ( $\mathrm{LpL}$ ) and Cholesterol ester transport protein. All these factors are likely cause of dyslipidemia in Diabetes mellitus. Moreover, insulin deficiency reduces the activity of hepatic lipase and several steps in the production of biologically active $\mathrm{LpL}$ may be altered in DM $[7,8]$.

The cause of dyslipidemia in diabetes mellitus type 2 might be due to insulin insensitivity or resistance affecting the apoprotein production by the liver which regulates the enzymatic activity of lipoprotein lipase and cholesterol ester transport protein [9]. A highly positive significant relationship of $\mathrm{HbA1C}$ with dyslipidemia was observed in the present Study. Erclays et al also re-ported positive correlation of $\mathrm{HbA1C}$ level with total cholesterol and triglycerides level in diabetic persons [10].

\section{CONCLUSION}

From Our study we would like to conclude that there is significant positive correlation is found between HBA1C and dyslipidemia. So HBA1C is not only a useful biomarker of long-term glycemic control but also a good predictor of lipid profile.

\section{REFERENCES}

[1]. Arshag D Mooradian. Dyslipidemia in type 2 diabetes mellitus. Nature Clinical Practice Endocrinology and Metabolism 2009;5(3):150-59.

[2]. Gimeno-Orna JA, Faure-Nogueras E and SanchoSerrano MA. Usefulness of total cholesterol/ HDLcholesterol ratio in the management of diabetic dyslipidaemia. Diabet Med 2005;22:26-31.

[3]. Anjana RM, Pradeep R, Deepa M, et al Prevalence of diabetes and prediabetes(Impaired fasting glucose and (or impaired glucose tolerance ) in urban and rural india :phase 1 results of the Indian Council of Medical Research -Indian Diabetes (ICMR=INDIAB) study:Diabetologia 2011;54(12): 3022-7.

[4]. Chandramohan P,Mohan V. High prevalence of Diabetes and Metabolic Syndrome Among policeman JAPI NOV.2008;56:837-38.

[5]. Friedewald WT, Levy RI, Fredrickson DS. Estimation of the concentration of low-density lipoprotein cholesterol in plasma without use of the preparative ultracentrifuge. Clin Chem 1972;18: 499-502.

[6]. Peterson KP, Pavlovich JG,Goldstein D, Little R, England J,Peterson CM.What is hemoglobin A1c ?An analysis of Glycated hemoglobins by electospray ionization mass spectrometry.Clin Chem.1998, 2008;44(9):1951-8.

[7]. Rosediani M, Azidah AK, Mafauzy M. Correlation between fasting plasma glucose, post prandial glucose and glycated haemoglobin and fructosamine. Med J Malaysia 2006;61:67-71.

[8]. Sultan A,Thuan JF,Avignon A.Primary Prevalence of cardiovascular events and type 2 diabetes should we prioritize our interventions?Diabetes Metab.2006;32:559-567.

[9]. Selvin E, Marinopoulos S,Berkenblit G, Rami T,Brancati FI,Powe NR.Metaanalysis: glycosylated hemoglobin and cardiovascular disease in diabetes mellitus.Ann Intern Med 2004;14:421-431.

[10]. Erclays F,Taneli F,Arslan B and Uslu Y.glycemic control,oxidative stress and lipid profile in children with type 1 diabetes mellitus. Arch. Med. Res 2004;35:134-140.

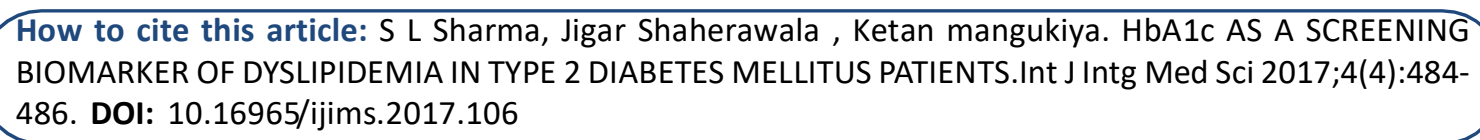

